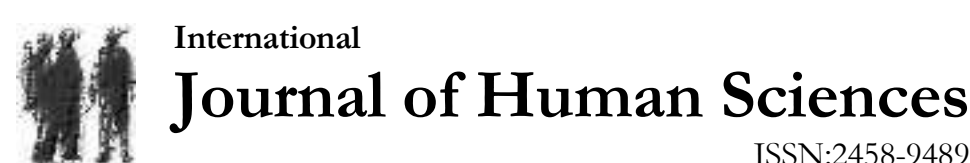

Volume 17 Issue 3 Year: 2020

\section{A research on the usage habits of food supplements in Thrace Region, Turkey}

\author{
Elif Velioğlu Er ${ }^{1}$ \\ Fatma Çoşkun ${ }^{2}$
}

\begin{abstract}
Aim: In this study, a thousand and ten people in the Thrace region in Turkey were examined to determine the usage patterns of food supplements and the factors that affect the preferences of them. Method: The respondents were selected by random sampling method and they were asked to answer questions about the issue either through social networks or face to face. The data obtained from the research were evaluated according to the general demographic groups and the results were expressed with graphs, percentages and statistical data. Findings: According to the research results; The majority of people have the habit of using food supplements, although not regularly. People prefer to consult medical officials with the intention of getting information about their food supplements preferences. It was understood that the product was paid attention to naturalness and quality. Conclusion: Increasing people's awareness about food supplements to prevent the use of unnecessary and incorrect food supplements is very important for public health. For this purpose, awareness raising activities should be carried out by authorized persons and organizations.
\end{abstract}

Keywords: Nutritional support; food supplement; food consumption; food knowledge.

\section{Introduction}

In addition to suppress hunger, problem of lack of nutrients such as carbohydrates, proteins, fats, vitamins and minerals, the term "food" is evaluated with potential beneficial effects needed for better mental and physical health and with reducing the risk of chronic diseases such as cancer, heart disease and obesity. Most chronic and infectious diseases are related to nutrition and it is possible to prevent $25-70 \%$ of these diseases with proper food consumption (El, 2010).

Nowadays, since no other foodstuff that contains the necessary substances for our body together cannot be detected yet, it is possible to obtain these substances only from the combination of different foodstuffs (Demirci, 2012). Due to physiological, psychological and socio-economic reasons, some groups in the society have to be fed with low-nutrient-based foods or based on uniform foods. Therefore, some nutrient (s) deficiency / insufficiency can be seen in groups of these people (Acar Tek and Pekcan, 2008). It may be possible to compensate for the deficiency of nutrients with food supplements. Today, however, many people use food supplements with their

1 Food Engineer Msc, Malkara Directorate of Food, Agriculture and Livestock Directorate, Turkey, elifvelioglu@windowslive.com, (D) Orcid ID: 0000-0002-2756-2631

2 Assistant Professor, Department of Food Engineering, Faculty of Agriculture, Tekirdağ Namık Kemal University, Turkey, fcoskun@nku.edu.tr, (ID) Orcid ID: 0000-0001-8889-363X 
own decisions in order to make the amount of nutrition sufficient, to be healthier and more vigorous, to cure their diseases or to prevent the disease. Dosage, administration, pharmacological effect, pharmacokinetic properties, etc. factors such as age, sex, genetic characteristics, diseases, etc. agents are also effective in the changes in the body of the substance used (Türkmen et al., 2014). In the Turkish Food Codex Notification on food supplements (Notification No: 2013/49) published by the Ministry of Agriculture and Forestry in the Official Gazette No: 28737 dated 16 August 2013, the definition of food supplements is as follows:

In order to supplement normal nutrition, food supplements are products of which the daily intake dose is determined by preparing the concentrates or extracts of the substances alone or in mixtures of capsules, tablets, lozenges, disposable powder packages, liquid ampoules, dropper bottles and other similar liquid or powder forms of concentrates or extracts alone or in mixtures of nutrients such as vitamins, minerals, proteins, carbohydrates, fiber, fatty acids, amino acids, bioactive substances and similar substances, substances of plant and animal origin having nutritional or physiological effects (Turkish Food Codex, 2013). Uncontrolled use of nutritional supplements can cause many problems.

In the literature, there are studies conducted in many countries, especially in the USA and European countries, to identify those who consume food supplements according to demographic dimensions (WHO, 2004). Consumer research conducted for this purpose in Turkey is extremely small.

\section{Purpose}

The aim of this study was to determine the awareness level of food supplements among 1010 respondents living in Thrace Region in Turkey.

\section{Method and Material}

The material of this study consists of online surveys and face-to-face surveys conducted with individuals from different socio-cultural backgrounds in the Thrace region inTurkey. The study was conducted in June-September 2018 on a voluntary basis with a total of 1010 people in order to obtain healthy food use habits and knowledge.

In order to obtain relevant data, the size of the sample was calculated using formula (1) (Malhotra, 1993).

$$
n=\frac{p \cdot q \cdot z_{\alpha / 2}^{2}}{D^{2}}
$$

$\mathrm{n}=$ Number of samples

$\mathrm{p}=$ the percentage occurrence of a state or condition ${ }^{\mathrm{A}}$

$\mathrm{q}=1-\mathrm{p}$

$\mathrm{D}=$ Margin of error $^{\mathrm{B}}$

$\mathrm{Z}_{\alpha / 2}=\% 99$

${ }^{\mathrm{A}} 0.5$ (will be considered since there is no prior knowledge of $\mathrm{p}$ )

B 0.04

According to the general rule applied in this type of sampling, $(p)=(q)=0,5$ was accepted. In this case, the largest possible sample volume is obtained with a constant sampling error and a degree of reliability. The sampling error was also taken as $4 \%$, which is conventionally used. If the sampling error (D) is assumed to be $4 \%$ and the degree of reliability is $99 \%(\mathrm{Z} \alpha / 1=2.53)$, the number of surveys (sample volume) to be performed was calculated using formula (2).

$$
n=\frac{0.5 \times 0.5 \times 2.53^{2}}{0.04^{2}}=\approx 1000
$$


The research data were obtained from the completed survey forms. Demographic characteristics of the participants were determined in the first part of the survey form. In order to determine the habits of food supplements, the sources they consulted and obtained information while making their preferences and other factors that affect the general knowledge levels, the qualifications of the respondents such as gender, income level, education level and age were also investigated. 5-point Likert scale (strongly agree, agree, undecided, disagree, strongly disagree) was used in the question about opinions on some judgments about food supplements. Research data were analyzed using SPSS 20.0 software. Significance level was accepted as 0.05 in the evaluation of statistical analyzes. Chi-square significance test and Kruskal Wallis test was used for statistical analysis.

\subsection{Respondents'profiles}

\section{Results}

In this study, $61.5 \%$ of the participants were female and $38-5 \%$ were male. The proportion of people with income between 2000 and 3000 was higher than in other groups. The proportion of those with $10000 €$ income was the least $(0.8 \%)$. The proportion of those between the ages of 30 39 was higher than the others. People over the age of 69 make up $0.8 \%$ of the participants. The proportion of university graduates (39.7\%) among the participants was higher than that of each other group. The proportion of illiterate group is the least. Demographic distributions of the respondents are shown in Table 1.

Table 1. Percentage distribution of respondents by demographic profile

\begin{tabular}{|c|c|c|}
\hline & Distribution & Percentage $(\%)$ \\
\hline \multicolumn{3}{|l|}{ Gender } \\
\hline Female & 621 & 61.5 \\
\hline Male & 389 & 38.5 \\
\hline \multicolumn{3}{|l|}{ Average monthly revenue } \\
\hline$\leq 1000 €$ & 107 & 10.6 \\
\hline 1000- $2000 €$ & 212 & 21 \\
\hline 2000-3000 & 339 & 33.6 \\
\hline 3000- $5000 €$ & 261 & 25.8 \\
\hline 5000- $10000 €$ & 83 & 8.2 \\
\hline 10000- $25000 €$ & 4 & 0.4 \\
\hline$\geq 25000 €$ & 4 & 0.4 \\
\hline \multicolumn{3}{|l|}{ Age Groups } \\
\hline$<18$ & 28 & 2.8 \\
\hline $18-29$ & 262 & 25.9 \\
\hline $30-39$ & 284 & 28.1 \\
\hline $40-49$ & 231 & 22.9 \\
\hline $50-59$ & 160 & 15.8 \\
\hline $60-69$ & 37 & 3.7 \\
\hline $69<$ & 8 & 0.8 \\
\hline \multicolumn{3}{|l|}{ Level of education } \\
\hline Illiterate & 1 & 0.1 \\
\hline Primary School & 20 & 2 \\
\hline Secondary School & 90 & 8.9 \\
\hline High School & 384 & 38 \\
\hline University & 401 & 39.7 \\
\hline Postgraduate/Doctorate & 114 & 11.3 \\
\hline
\end{tabular}


Velioğlu Er, E., \& Çoşkun, F. (2020). A research on the usage habits of food supplements in Thrace Region, Turkey. Journal of Human Sciences, 17(3), 877-888. doi:10.14687/jhs.v17i3.5999

\subsection{BMI values of respondents}

BMI values were determined by using the height-weight values of the surveyed people. The World Health Organization Body Mass Index (BMI) Classification $\left(\mathrm{kg} / \mathrm{m}^{2}\right)$ is taken into consideration. Accordingly, $1.3 \%$ of the respondents had a BMI of less than 18.5 (weak), $9.3 \%$ of the respondents had a BMI greater than 30 (obese), 63.6\% of the respondents had a BMI value between 18.5 and 24.9 (at normal weight), while 25.8\% had a BMI value between 25-29.9 (overweight).

\subsection{Whether to spor regularly}

"Do you do sports regularly? How often do you play sports?" when asked; it was determined that $45 \%$ of the respondents did not do sports, $25.9 \%$ did sports once a week, $23.3 \%$ did sport 2-3 days a week, 3.8\% did sport 4-5 days a week, 2.1\% did sport every day. Kruskal Wallis test was used for statistical analysis. According to the results, it was observed that the relationship between sporting and respondents' mean BMI was not significant $(\mathrm{P}>0.05)$.

\subsection{State to have chronic diseases}

When respondents were asked if they had chronic diseases, $17.8 \%$ of the respondents stated that they had one or more chronic diseases. These are allergy, asthma, anxiety Disorders, beta Thalassemia carriage, diabetes, epilepsy, FMF (Familial Mediterranean Fever), gastritis, reflux, hepatitis B carrier, hypertension, thyroid hormone disorder, rheumatoid arthritis, heart failure, chronic obstructive pulmonary disease, heart disorders include parkinson's, migraine, seborrheic dermatitis, obesity, iron deficiency.

\subsection{Food consumption of respondents}

Food consumption habits of the respondents are shown in Figure 1.

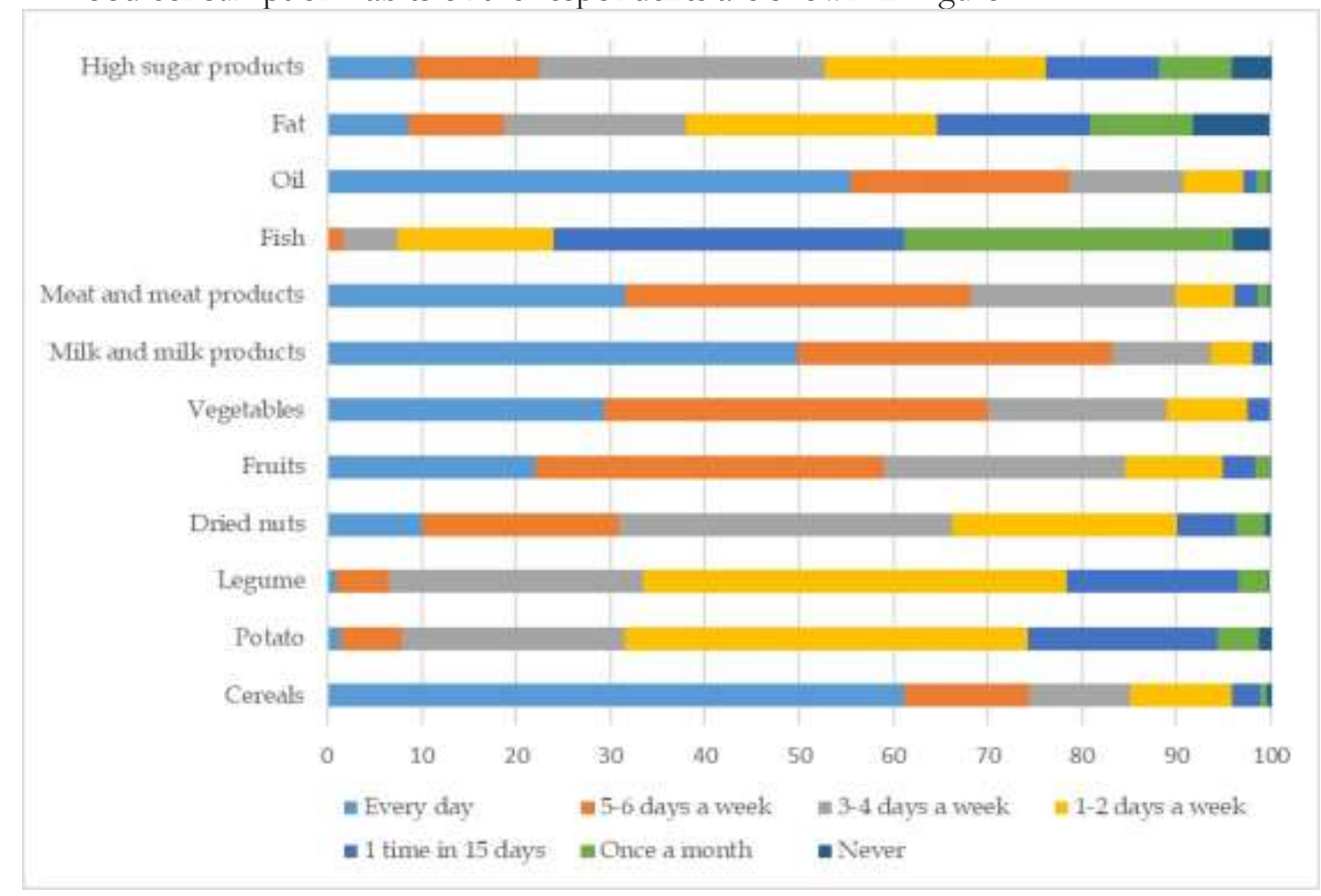

Figure 1. Food consumption habits of the respondents (\%)

It was found that the majority of the respondents consumed meat and meat products, milk and dairy products, vegetables and fruits, cereals, oil and legumes at appropriate frequencies for optimal nutrition. It has been determined that the consumption of high sugar products, which have been proven by many scientific studies that increase the risk of coronary heart diseases, obesity and Type 2 diabetes is frequent. When the consumption of fats, which have very 
Velioğlu Er, E., \& Çoşkun, F. (2020). A research on the usage habits of food supplements in Thrace Region, Turkey. Journal of Human Sciences, 17(3), 877-888. doi:10.14687/jhs.v17i3.5999

important tasks in the body and which is as important as the amount of consumption, is examined, it is determined that the consumption of saturated fat containing solid fat is high.

According to the Kruskal Wallis test results, it was observed that the relationship between high sugar consumption and respondents' mean BMI was significant $(\mathrm{P}<0.05)$. The relationship between mean BMI of meat and egg consumption was found to be significant $(\mathrm{P}<0.05)$. It was observed that the relationship between legume, fruit and vegetables consumption and respondents' mean BMI was insignificant $(\mathrm{P}>0.05)$.

\subsection{Use food supplements of respondents}

When respondents were asked whether they used food supplements; $38.2 \%$ of them stated that they had used or used food supplements before and $61.8 \%$ of them had not used food supplements. When the relationship between the income status of the respondents and the use of food supplements was examined statistically with the Chi-square test, a significant relationship was found between them $(\chi 2: 16.533, \mathrm{P}<0.05)$. The relationship between the educational status of the respondents and the use of food supplements was significant. $(\chi 2: 14.911, \mathrm{P}<0.05)$. The relationship between gender and food supplement use was also significant. $(\chi 2: 52.918, P<0.05)$. The relationship between age and use of food supplements was significant $(\chi 2: 55.131, P<0.05)$. The relationship between having chronic diseases and use of food supplements was significant $\left(\chi^{2}: 63.807, \mathrm{P}<0.05\right)$.

\subsection{Reasons for not using food supplements}

When 624 respondents who did not use food supplements were asked about the reasons for not using food supplements, 431 (69.1\%) of them 'I do not think I need', 147 (23.6\%) 'I think it is not appropriate to take food supplements from outside', 44 (7.1\%) 'My doctor did not recommend', $2(0.3 \%)$ 'I do not use because of a special disease' replied that.

\subsection{Expectations from the use of food supplements}

The answers to the expectations regarding the use of food supplements directed to 386 people using food supplements are as follows;

$200(29.1 \%)$ 'I want to feel good', $138(20.1 \%)$ 'I want to improve my mental performance', $183(26.6 \%)$ 'I want to be resistant to diseases', $46(6.7 \%)$ 'I want to use it to delay the effects of aging' and $121(17.6 \%)$ 'I use it to solve a particular health problem'. Most people use them for multiple purposes. Others stated that they use it for pregnancy and weight loss.

\subsection{Opinions on judgments about food supplements}

When the respondents were asked about their opinions about three different jurisdictions regarding the use of food supplements (Likert scale of 5), a high percentage of 'strongly disagree' and 'disagree' responses were obtained. Results shown in Figure 2. So, it can be understood that people have a high level of awareness about the highest amount of vitamins used in food supplements.

\subsection{Using more than one food supplements}

When asked if they use more than one food supplement, $68.2 \%$ of 386 respondents who stated that they use food supplement stated that they did not use more than one food supplement. hose who stated that they use more than one food supplements make up $31.8 \%$ of those using food supplements. 
Velioğlu Er, E., \& Çoşkun, F. (2020). A research on the usage habits of food supplements in Thrace Region, Turkey. Journal of Human Sciences, 17(3), 877-888. doi:10.14687/jhs.v17i3.5999

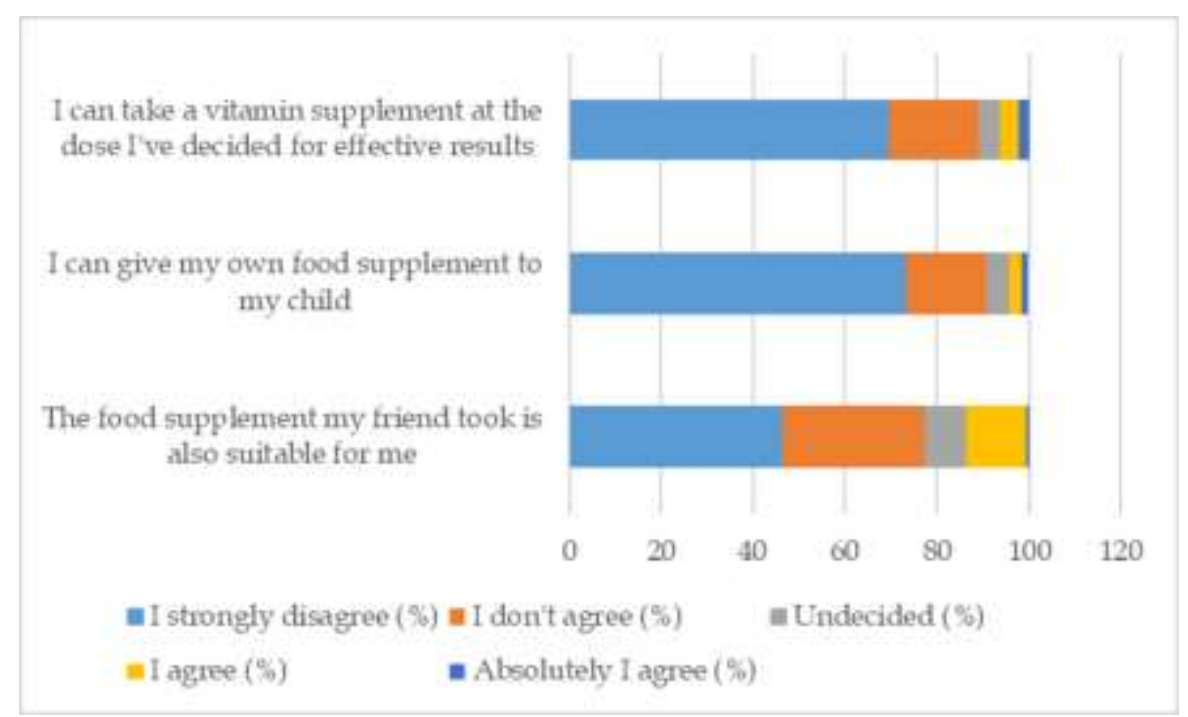

Figure 2. Proportional distribution of judgments related to food supplements (\%)

\subsection{Whether the opinion of the health authority has been obtained on the use of more than one food supplement}

When 121 people who stated that they used more than one food supplements were asked to get information from any health authorities about the use of these products, it was determined that $88.4 \%$ of the respondents answered 'Yes, I consulted my doctor / pharmacist'.

\subsection{Priority sources of information on the use of food supplements}

In this regard, $55.5 \%, 24.8 \%, 12 \%$ and $7.7 \%$ of the respondents stated that they used food supplements, health workers / people who have received training on the subject, circle of friends, visual media and print media (books, magazines), brochures, etc., respectively.

\subsection{The primary consideration in the purchase of food supplements}

Respondents using food supplements (386 people) were report that they care natural (56.2\%), (19.4\%) quality, (15\%) brands, $(8.5 \%)$ prices and $(0.8 \%)$ domestic production.

\subsection{Being influenced by ads when choosing a food supplement}

"Are you affected by ads when choosing food supplements?" when asked, those who say 'No', 'sometimes', 'I didn't notice', 'yes' were 33.7\%, 32.6\%, 26.2\% and 7.5\% respectively.

\subsection{Level of knowledge about food supplements}

Some questions were asked to the participants to measure the level of knowledge of food supplements. The distribution of the answers given to these questions is shown in the Figure (3). The majority of participants 'Some food supplements are not suitable for continuous use' (\%32.4). The group constituting 18\% of the total participants said 'There is a notification which specifies the product properties in order to ensure the production, preparation, processing, storage, storage, transportation and supply of food supplements in a hygienic manner according to the technique'. 
Velioğlu Er, E., \& Çoşkun, F. (2020). A research on the usage habits of food supplements in Thrace Region, Turkey. Journal of Human Sciences, 17(3), 877-888. doi:10.14687/jhs.v17i3.5999

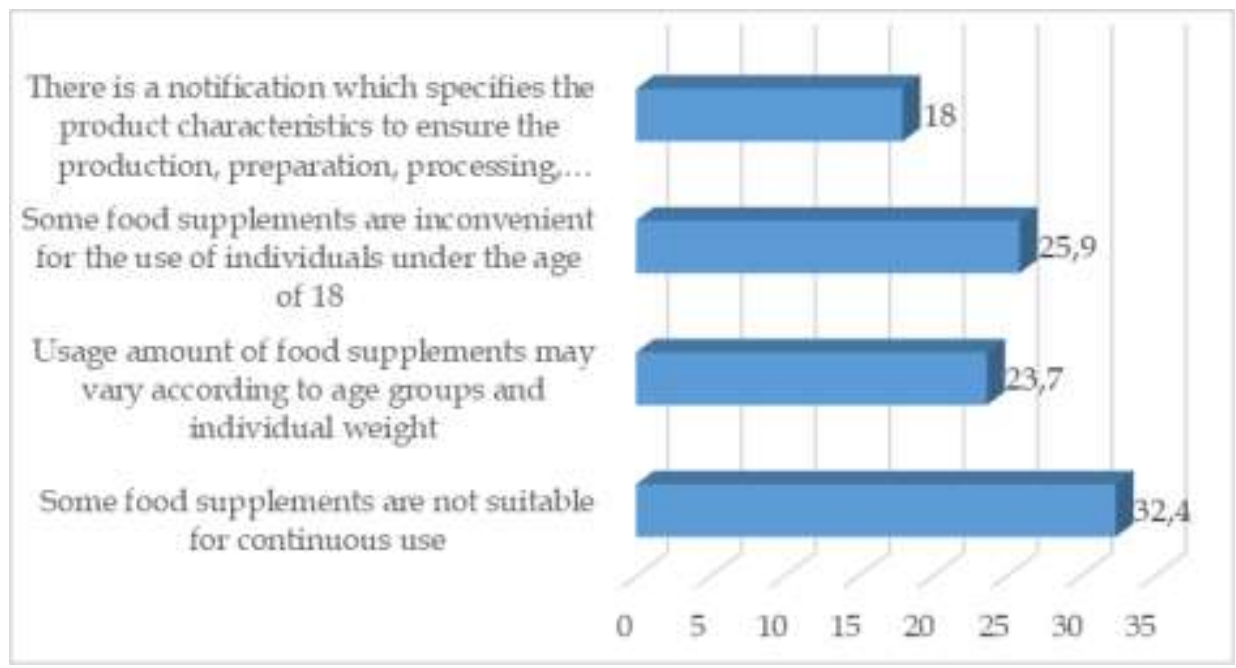

Figure 3. Proportional distribution of knowledge on food supplements (\%)

Respondents may have learned from the health professionals that the continuous use of food supplements is inconvenient, the amount of use by age and weight group, the information about the presence of food supplements that are prohibited in children. However, they are unaware of the existence of a notification that includes the production of food supplements, the stages after production and the conditions of food supplements at the market stage. This can be explained by the fact that food supplements that are not included in the pharmaceutical class are followed by the Ministry of Agriculture and Forestry rather than the Ministry of Health and by the low level of knowledge of individuals, as no effective public spot was prepared. A public service advertising can be prepared to inform consumers.

\subsection{The level of knowledge of consumers related to the organization that carry out the production and control of food supplements}

When the participants' level of knowledge about the organization that carry out the production and control of food supplements is questioned, $\% 41.9, \% 29.8, \% 25.1, \% 2.8, \% 0.4$ of them said Ministry of Agriculture and Forestry, Ministry of Health, I don't know, State Supervisory Authority, Universities, respectively. Proportional distribution of the level of knowledge about the organization that carry out the production and control of food supplements in relation to the education factor is shown in Figure 4. The fact that most people know as the Ministry of Health may be due to the fact that the food inspection and control task has been temporarily transferred to this institution in previous years. The dominance of the idea that food supplements are included in the pharmaceutical group in terms of appearance and use may also have caused people to know the Ministry of Health as a competent institution. When the level of knowledge is compared with the educational level; it is observed that there is an increase in the level of correct knowledge about the subject with increasing education level. These results can be explained that especially the people with low educational background do not have enough information about the subject and they say ' I don't know' and there is a general information pollution about the subject. 
Velioğlu Er, E., \& Çoşkun, F. (2020). A research on the usage habits of food supplements in Thrace Region, Turkey. Journal of Human Sciences, 17(3), 877-888. doi:10.14687/jhs.v17i3.5999

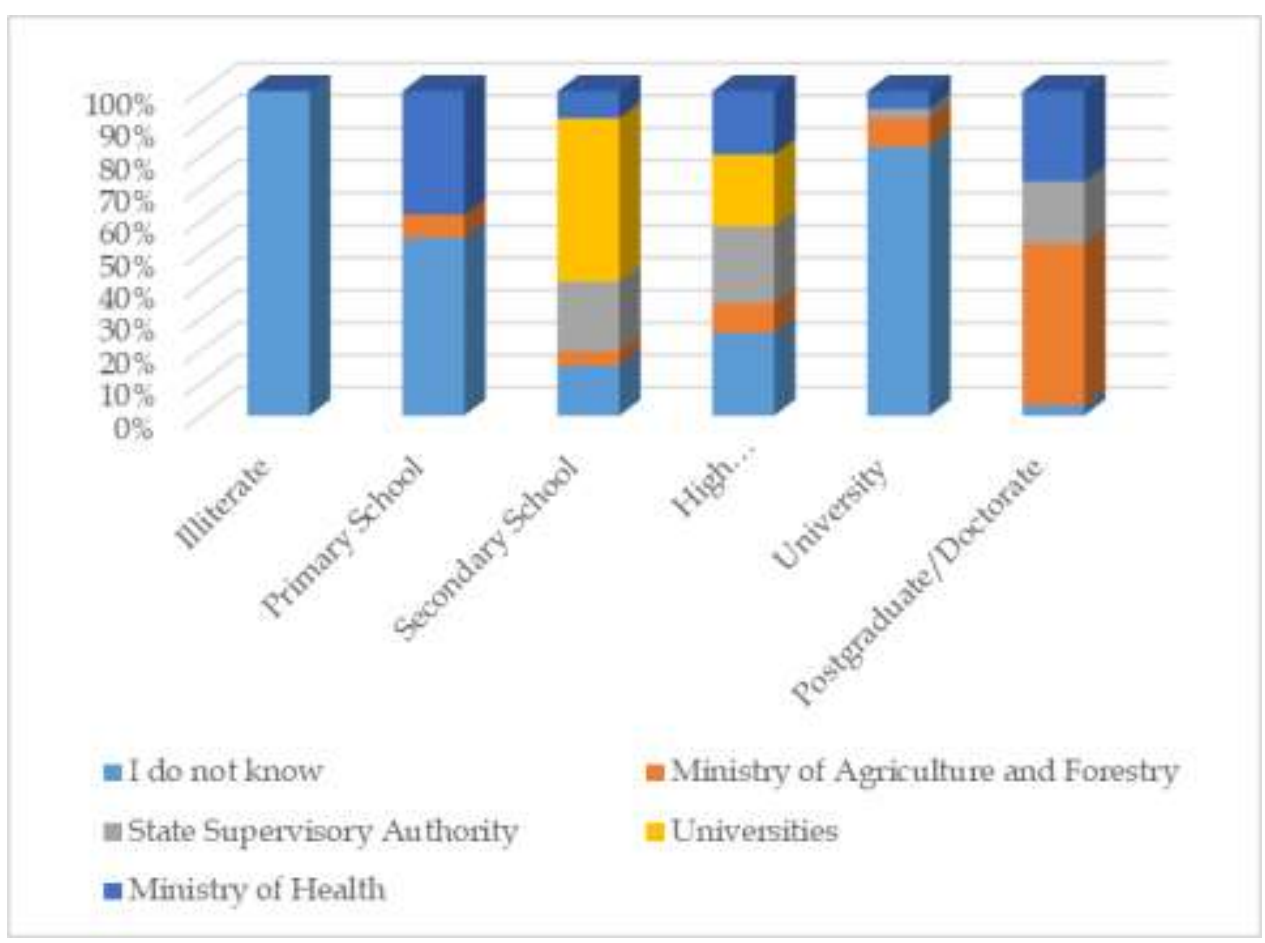

Figure 4. Proportional distribution of the level of knowledge about the organization that carry out the production and control of food supplements in relation to the education factor $(\%)$

\section{Discussion}

In study conducted by Giammarioli et al. (2012) in Italy, with regard to medical conditions, most participants reported no specific disease and considered their health status good or fair, with no or low levels of stress. Among those who reported diseases, high blood pressure, anxiety/depression, high cholesterol and joint diseases were the main declared diseases; less frequently declared were osteoporosis, CVD and diabetes.

In a study conducted in Finland, Germany, Italy, Spain, Romania and England in 2014, $39.3 \%$ of male participants and $35.6 \%$ of female participants were found to use plant food supplements periodically. The proportion of casual users and those using when their condition deteriorates is similar in both sexes. $38.8 \%$ of the participants aged $18-59$ and $33 \%$ of the participants over 60 years of age use plant food supplements periodically. When $25.2 \%$ of the participants over 60 years of age get worse, $21.4 \%$ use plant food supplements for other reasons In the same study, the proportion of people using plant food supplements randomly (38.4\%) was the highest in United Kingtom, the rate of periodical using (50.7\%) was the highest in Germany and the percentage of using in poor conditions (\%30.7) was the highest in Italy. The rate of periodical users $(14.6 \%)$ and the proportion of users who deteriorated $(16.1 \%)$ were the lowest in Spain. In Spain, the rate of users for other reasons $(46 \%)$ is higher than in other countries (Garcia-Alvarez et al., 2014).

In study conducted by Giammarioli et al. (2012) in Italy, 49\% of the participants reported that they used food supplements and 51\% reported that they did not use food supplements. In the same study, $56 \%$ of food supplement users were women. People between the ages of 18-45 have the highest rate of food supplement users. Those at university and higher education level, people with <18.5 BMI and high income group have a high rate of using food supplements.

In a study in US, it has been found that half of adults use one or more food supplements. In that study, it was stated that people using food supplements are elderly, have low body mass index, physically active, low smoking rate, and have good education and socioeconomic status (Bailey et al., 2013; Dickinson et al., 2014; Atalay and Erge, 2018). 
Velioğlu Er, E., \& Çoşkun, F. (2020). A research on the usage habits of food supplements in Thrace Region, Turkey. Journal of Human Sciences, 17(3), 877-888. doi:10.14687/jhs.v17i3.5999

Bora (2014) found that $43 \%$ of sports instructors interested in bodybuilding in the gym use vitamin-mineral supplements and $57.57 \%$ do not use them. In the study conducted by Ergen and Bozkurt Bekoğlu (2016), it was determined that the respondents with higher income level than 673 people aged 18 and over living in Istanbul use glucosamine and multivitamins more frequently. In their study, it was determined that fish oil recognition increased only with respect to rising income. Their studies support the results obtained from this study.

Turhan (2008), in his study investigating vitamin usage habits and the factors affecting these habits in Istanbul, asked the group of 1000 respondents why they did not use vitamins, 16.9\% stated that they did not use it because they had a special condition, $25.4 \%$ stated that they did not use it because they did not use it, $25.2 \%$ who said they did not use it because they thought it was balanced nutrition, $16.2 \%$ who said they did not use it, $19.2 \%$ who stated that they did not recommend the doctor, In his study, $22.3 \%$ of the respondents thought that it was not appropriate to take vitamins from outside. The results of that study support those of this study. In addition, respondents who answered ' $I$ think it is not appropriate to take food supplements from outside' may be considered biased about the effectiveness and safety of food supplements.

In a study conducted by Conner et al. (2001) with 303 respondents in the UK, users of nutritional supplements stated that they bought these products to protect themselves from illnesses and to help them to be healthy and that they considered this to be the best thing they could do for themselves. Only $1 \%$ of them stated that they used the nutritional support product with the prescription given by the doctor. In the study conducted by Turhan (2008), vitamin usage habits and factors affecting these habits were investigated in Istanbul, When 1000 respondents were asked about the expected benefits of vitamin use, $38.1 \%$ of the respondents ' $\mathrm{I}$ want to feel good', $24.3 \%$ 'I want to be resistant to diseases', $12.9 \%$ 'I want to delay the effects of aging', $18.1 \%$ 'to solve the health problem' and $6.6 \%$ said 'for other reasons'. The results of that study support those of this study. In a study, the main reasons for consuming nutritional supplements are immune strengthening (30\%), fatigue prevention $(22 \%)$, physical $(15 \%)$ and mental (mental) (11\%) performance. Sleep disorders were found to be the last $(4 \%)$ among the causes of consumption (Ergen and Bozkurt Bekoğlu, 2016). In the study of Bülbül et al. (2014) respondents stated that they use vitamins and minerals for strengthened the immune system $(30.7 \%)$, protection from cancer $(17.7 \%)$, delaying old age $(14.6 \%)$, comfortable menopause $(12.1 \%)$, strengthening the body in winter $(4.5 \%)$, sports performance $(3.9 \%)$, healthy growth of babies $(3.4 \%)$ and medical treatment $(2.5 \%)$.

In a study by Bailey et al. (2013), it was reported that approximately 12,000 people over the age of 20 were studied to investigate the use of food supplements in the United States. It is reported that women use calcium supplements for bone health $(36 \%)$ and men prefer reinforcements for heart health or lower cholesterol (18\%). Adults over the age of 60 are reported to use food supplements for heart, bone, joint and eye health. In another study, it was reported that food supplements are used for purposes such as providing health support and completing nutritional deficiencies (Dickinson et al., 2014). It is stated that food supplements are used for purposes such as performance improvement, cosmetic or balanced nutrition, strengthening the immune system and improving certain diseases (Atalay and Erge, 2018; Petroczi et al., 2011; Soare et al., 2014; Rautiainen et al., 2016).

In one study, $35.5 \%$ of the people stated that they consulted a doctor considering that their child was malnourished when choosing vitamins for their children. The doctor recommended that $27.2 \%$ of people use vitamins for health problems. The number of people using vitamins without consulting a doctor is not small (14.7\%). $22.8 \%$ of the total respondents do not approve the use of vitamins in children (Coşkun and Turhan, 2010).

In study conducted by Giammarioli et al. (2012) in Italy, forty-four per cent of users used only one category of food supplement users; in particular, $29 \%$ used two different categories and $25 \%$ three or more, with no significant differences between men and women. 
In the study of Cosskun and Turhan (2010), the factors affecting the vitamin selection of the respondents were examined. The ratio of those who answered ' $\mathrm{I}$ do it with the help of my doctor' was $31.4 \%$, the rate of those who answered 'by research myself' was $19.3 \%$, the rate of those who responded 'by the recommendation of a friend' was $20.3 \%$, and the rate of those who answered 'through counselors in vitamin stores' was $20 \%$. In a study conducted in Ankara (in Turkey), it was determined that 137 people using food supplements all used more than one food supplements. When asked about the intended use of the products, men were asked to improve fitness, performance and immunity, respectively; in women, responses to increase immunity, retard vitality and aging. When asked 'What kind of impact do you think additional products have on health conditions?', $67.9 \%$ of respondents said they felt too much benefit and $9.5 \%$ were uncertain about the effect of the products. Nine of the respondents evaluated the effects of these products as negative and stated negative effects as allergic reactions, loss of appetite, intestinal problems and worsening hypertension (Ünsal et al., 2010). The results obtained in this study are similar to the results obtained in other studies. It is thought that consumers should use these products with the instructions of health workers while using food supplements, and these products which are not used in appropriate doses may have negative effects on health.

Most users think that food supplements that are not defined as medicines will not have side effects. However, it should be noted that food supplements can also cause side effects and interactions. Food supplements are pharmacological, such as medicines, and are desirable for use under doctor or dietician control. The reason of this; the chemical component, side effects or potential drug interactions of food supplements (McWhorter, 2009).

In his study in Istanbul, Turhan (2008) directed the question "What are the sources of information about vitamins?' to 1000 respondents. The answers given were my doctor $(31.5 \%)$, books $(12.5 \%)$, media $(12.7 \%)$, internet $(16.4 \%)$, pharmacists and product consultants $(26.9 \%)$. In the study conducted by Neuhouser et al. (Neuhouser et al., 1999), general health information sources of the respondents were doctors and nurses (71\%), print media sources such as magazines and newspapers (slightly over 50\%), television and radio (40\%), family and friends $(23 \%)$. In the study of Bülbül et al. (2014), television (43.5\%), health care workers (19.2\%), friends (12.8\%), the internet $(4.5 \%)$ and books $(3.7 \%)$ are sources of information. The findings obtained are similar to those of this study. In the study conducted by Yilmaz in 2019 in Süleymanpaşa district of Tekirdağ, a province of Thrace, $53.7 \%$ of the respondents stated that they took dietary supplements on the doctor's recommendation. The result in our study is similar to her.

The majority of people under the age of 60 have stated that they use nutritional supplements to prevent colds and fatigue.

It was concluded that while male users use multivitamins more frequently, female users receive more calcium supplements than men. While dieticians and nutritionists were less effective in recommending complementary use, it was observed that doctors were the most effective group especially for elderly individuals and women (Creighton and Seaborn, 1997). The primary source of information that consumers apply for the use of food supplements is that health professionals / trained people may be the main reason for trust in people in this occupational group such as doctors, pharmacists, etc.

In a study, when respondents were asked the question "What affects your brand choice most?" They were answer as (27.9\%) recognized, 37.4\% reliable, 10.5\% product content, 12\% price and 12.2\% referral (Coşkun and Turhan, 2010). While the groups with better socio-cultural structure give importance to the recognition of the product as well as the reliability of the product, the other groups prefer to be more reliable. People stated that they give importance to the fact that food supplements are natural. People may think that natural products with higher prices than synthetic products are more effective and safer for their health.

According to the results obtained by Dikmen (2006), 12.7\% of the children immediately buy and consume the food and drinks they watch on television advertisements. 19.6\% of children do not immediately buy and consume the food and drinks they watch on television 
Velioğlu Er, E., \& Çoşkun, F. (2020). A research on the usage habits of food supplements in Thrace Region, Turkey. Journal of Human Sciences, 17(3), 877-888. doi:10.14687/jhs.v17i3.5999

advertisements. $65.6 \%$ of children sometimes take and consume immediately. In the study of Çerçi (2009), it was stated that the desire of children to have the products they see in advertisements was 'sometimes I want' (52.5\%), 'I want yes' (35\%) and 'I don't want no' (12.4\%). The results are similar to the results of this study.

\section{Conclusions and recommendations}

Nowadays, diet, living conditions and stress factor, the idea of being cautious in finding or preventing certain diseases, encourages people to use various food supplements from time to time. Depending on the amount of use, there are products that may have detrimental effects on people when used with other medicines or as a combination of more than one food supplement, these are products that need to be thoroughly investigated and their reliability guaranteed. In addition, doctors, pharmacists, dietitians and other occupational groups in the health sector should be informed periodically about food supplements and scientific developments related to these products. It is important for the public health and future generations that the studies on this subject are carried out meticulously.

\section{References}

Acar Tek, N., Pekcan, G. (2008). Should Nutritional Supplements be Used?. Ministry of Health Publications, Number: 727, Ankara, Turkey, p.32.

Atalay, D., Erge, H.S. (2018). Gida takviyeleri ve sağlık üzerine etkileri. Food and Health, 4 (2): 98111. doi: $10.3153 /$ FH1 8010

Bailey, R.L., Gahche, J.J., Miller, P.E., Thomas, P.R., Dwyer, J.T. (2013). Why US adults use dietary supplements. JAMA Internal Medicine, 173 (5): 355-361. doi: 10.1001/jamainternmed.2013.2299

Bora, Z. (2014). Determination of the nutrition context and nutrition supplements used by the bodybuilding coaches at sports club, Department of Nutrition and Dietetics, Institute of Health Sciences, Başkent University, Master's Thesis, Ankara, Turkey.

Bülbül, S., Sürücü, M., Aşık, G. (2014). Vitamin kullanım alışkanlıkları ve etkileyen faktörler. Çocuk Sağlğg ve Hastaliklar Dergisi, 57 (4): 241-245.

Çerçi, F. (2009). A Research on determining the relationship between children's understanding and perciption level of advertising and demographic variables in Mersin, Department of Business Administration, Social Sciences Institute, Çukurova University, Master's Thesis, Adana, Turkey. 2009.

Conner, M., Kirk, S.F., Cade, J.E., Barrett, J.H. (2001). Why do women use dietary supplements? The use of the theory of planned behaviour to explore beliefs about their use. Social Science \& Medicine, 52 (4): 621-633. doi: 10.1016/S0277-9536(00)00165-9

Coşkun, F., Turhan, H. (2010). A research on vitamin usage habits and factors affecting this habits in İstanbul. Marmara Pharmacentical Journal, 14 (1): 21-28. doi: 10.12991/201014461

Creighton, A., Seaborn, C.D. (1997). Vitamin and mineral supplementation practices of middle aged and elderly people of St. Paul and Mineapolis, Minnesota. Journal of the American Dietetic Association, 96 (9): A77. doi: 10.1016/S0002-8223(96)00583-4

Demirci, M. (2012). Food Chemistry. Food Technology Association Publications, Number: 40, Tekirdağ, Turkey, p.290.

Dickinson, A., Blatman, J., El-Dash, N., Franco, J.C. (2014). Consumer usage and reasons for using dietary supplements: report of a series of surveys. Journal of the American College of Nutrition, 33 (2): 176-182. doi: 10.1080/07315724.2013.875423

Dikmen, D. (2006). Nutritional behaviours of primary school student (sample of three primary Schools-Keçiören), Department of Health Education, Institute of Health Sciences, Ankara University, Master's Thesis, Ankara, Turkey. 
Velioğlu Er, E., \& Çoşkun, F. (2020). A research on the usage habits of food supplements in Thrace Region, Turkey. Journal of Human Sciences, 17(3), 877-888. doi:10.14687/jhs.v17i3.5999

El SN (2010) Optimum Nutrition Approach in Product Development. (https://docplayer.biz.tr/369511-Urun-gelistirmede-optimum-beslenme-yaklasimi.html (accessed on 06 January 2019).

Ergen, A., Bozkurt Bekoğlu, F. (2016). Views regarding dietary supplements in Turkey and a research to profile the consumers. Journal of Business Research Turk, 8 (1): 323-341. doi: 10.20491/isader.2016.147

Garcia-Alvarez, A., Egan, B., de Klein, S., Dima, L., Maggi, F.M., Isoniemi, M. et al. (2014). Usage of plant food supplements across six European Countries: Findings from the PlantLIBRA consumer survey. PLOS ONE, 9 (3): e92265. doi: 10.1371/journal.pone.0092265

Giammarioli, S., Boniglia, C., Carratu, B., Ciarrocchi, M., Chiarotti, F., Mosca, M., Sanzini, E. (2012). Use of food supplements and determinants of usage in a sample Italian adult population. Public Health Nutrition, 16 (10): 1768-1781. doi: 10.1017/S1368980012004314

Malhotra, Y. (1993). Controlling copyright infringements of intellectual property: the case of computer software- Part Two. Journal of Systems Management, 45 (7): 12-19.

McWhorter, L.S. (2009). Dietary supplements for diabetes: an evaluation of commonly used products. Diabetes Specialist, 22 (4): 206-213. doi: 10.2337/diaspect.22.4.206

Neuhouser, M.L., Patterson, R.E., Levy, L. (1999). Motivations for using vitamin and mineral supplements. Journal of the American Dietetic Association, 99 (7): 851-854. doi: 10.1016/S00028223(99)00202-3

Petroczi, A., Taylor, G., Naughton, D.P. (2011). Mission Impossible? Regulatory and enforcement issues to ensure safety of dietray supplements. Food and Chemical Toxicology, 49: 393-402. doi: 10.1016/j.fct.2010.11.014

Rautiainen, S., Manson, J.E., Lichtenstein, A.H., Sesso, H.D. (2016). Dietary supplements and disease prevention - a global overview. Nature Reviews Endocrinology, 12: 407- 420. doi: $10.1038 /$ nrendo. 2016.54

Soare, A., Weiss, E.P., Holloszy, J.O., Fontana, L. (2014). Multiple dietary supplements do not affect metabolic and cardiovascular health. Aging, 6 (2): 149-157. doi: 10.18632/aging. 100597

Turhan, H. (2008). A research on vitamin usage habits in Istanbul and determine its affecting factors, Department of Food Engineering, Graduate School of Natural and Applied Sciences, Namık Kemal University, Master's Thesis, Tekirdağ, Turkey.

Turkish Food Codex, (2013). Communiqué on Supplementary Foods. Official Gazette Number: 28737, http://www.resmigazete.gov.tr/eskiler/2013/08/20130816-16.htm (accessed on 05 January 2019).

Türkmen, Z., Türkdoğru, S., Mercan, S., Aç1kkol, M. (2014). Herbal products and support food products content description of medicolegal aspects. The Bulletin of Legal Medicine, 19 (1): 3848.

Ünsal, G.N., Özdemir, G., Ersoy, G. (2010). The assessment of the consumer awareness in nutritional support products usage. Firat University Medical Journal of Health Science,_24 (2): 8188.

WHO, (2004). Issues Guidelines for Herbal Medicines. Bulletin of the World Health Organization, 82 (3): 236-238.

Yilmaz, E. (2019). Consumers' attitudes and behaviors regarding dietary supplements. Fresenius Environmental Bulletin, 28 (10): 7388-7393. 